\title{
Clear Cell Intrahepatic Cholangiocarcinoma
}

National Cancer Institute

\section{Source}

National Cancer Institute. Clear Cell Intrahepatic Cholangiocarcinoma. NCI Thesaurus.

Code C43848.

A morphologic variant of intrahepatic cholangiocarcinoma composed of malignant

glandular epithelium, an abundant fibrous stroma, and the presence of clear cells. Clinical symptoms include abdominal pain, weight loss and malaise. 